

http://www.e-journals.net
ISSN: 0973-4945; CODEN ECJHAO

E-Journal of Chemistry

Vol. 5, No.4, pp. 820-831, October 2008

\title{
Adsorption of Chromium Ion by Acid Activated Low Cost Carbon-Kinetic, Mechanistic, Thermodynamic and Equilibrium Studies
}

 \\ ${ }^{\S}$ Department of Chemistry, \\ H. H. The Rajah's Government Arts College, Pudukkottai-622001, India. \\ \#Department of Chemistry, M. R. Govt. Arts College, Mannargudi-614001. \\ arivu3636@yahoo.com
}

Received 29 November 2007; Accepted 20 January 2008

\begin{abstract}
A carbonaceous adsorbent prepared from an indigenous waste by acid treatment was tested for its efficiency in removing chromium ion. The parameters studied include agitation time, initial chromium ion concentration, carbon dose, $\mathrm{pH}$ and temperature. The adsorption followed first order reaction equation and the rate is mainly controlled by intra-particle diffusion. Freundlich and Langmuir isotherm models were applied to the equilibrium data. The adsorption capacity $\left(\mathrm{Q}_{\mathrm{m}}\right)$ obtained from the Langmuir isotherm plots were 27.40, 26.06, 26.06 and 26.17 $\mathrm{mg} / \mathrm{g}$ respectively at an initial $\mathrm{pH}$ of 7.0 at $30,40,50$ and $60^{\circ} \mathrm{C}$. The temperature variation study showed that the chromium ion adsorption is endothermic and spontaneous with increased randomness at the solid solution interface. Significant effect on adsorption was observed on varying the $\mathrm{pH}$ of the chromium ion solutions. Almost $70 \%$ removal of chromium ion was observed at $60^{\circ} \mathrm{C}$. The Langmuir and Freundlich isotherms obtained, positive $\Delta \mathrm{H}^{0}$ value, $\mathrm{pH}$ dependent results and desorption of dye in mineral acid suggest that the adsorption of chromium ion on PDC involves physisorption mechanism.
\end{abstract}

Keywords: Activated carbon (PDC), Chromium ion, Adsorption isotherms, Equilibrium, Kinetic and Thermodynamic parameters, Intraparticle diffusion and Regeneration pattern

\section{Introduction}

Wastewater quality can be defined by physical, chemical or biological characteristics and it is given in the table Wastewater generally contains toxic inorganic and organic pollutants. Inorganic pollutants consist of mineral acids, inorganic salts, finely divided metal trace elements, cyanides, nutrients and organ metallic compounds. Some of the trace elements play essential roles in biological processes, but at higher concentrations, they may be toxic to biota; 
they disturb the biochemical processes and cause hazards. These elements include metals $(\mathrm{Cd}$, $\mathrm{Cr}, \mathrm{Co}, \mathrm{Cu}, \mathrm{Zn}, \mathrm{Pd}, \mathrm{Hg}, \mathrm{Ni}, \mathrm{Ag}$ ) and metalloids (Se, As, Sb). Most of the trace elements are transition metals with variable oxidation states and coordination numbers. These metals form complexes with organics in the environment thereby increasing their mobility in the biota and manifest toxic effects. Although there are metals that have inherent ability to antagonize the essential functions of other elements, the heavy load of contaminants arising from human activity exceeds the ability of self-purification of aqueous environment.

A number of treatment processes for the removal of heavy metal ions from aqueous solutions have been reported, mainly ion-exchange, electrochemical reduction, evaporation, solvent extraction, reverse osmosis, chemical precipitation, membrane filtration, adsorption, etc. Depending on the nature of the aqueous effluents, flow rates and metal ion concentrations, the industrial application of these processes is restricted by the operating costs or by the inefficiency of the technique ${ }^{1-3}$.

The present study undertaken to evaluate the efficiency of a carbon adsorbent prepared from acid activated pandanus carbon for removal of chromium ion in aqueous solution. In order to design adsorption treatment systems, knowledge of kinetic and mass transfer processes is essential. In this paper, we have reported the applicability of kinetic and masstransfer models for the adsorption of chromium ion onto acid activated carbon.

\section{Experimental}

Adsorbent material

The dried pandanus stem was carbonized with concentrated sulphuric acid in the weight ratio of $1: 1(\mathrm{w} / \mathrm{v})$. Heating for twelve hours in a furnace at $600^{\circ} \mathrm{C}$ has completed the carbonization and activation. The resulting carbon was washed with distilled water until a constant $\mathrm{pH}$ of the slurry was reached. Then the carbon was dried for four hours at $100^{\circ} \mathrm{C}$ in a hot air oven. The dried material was ground well to a fine powder and sieved.

\section{Adsorption dynamic experiments}

\section{Batch equilibration method}

The adsorption experiments were carried out in a batch process at $30,40,50$ and $60^{\circ} \mathrm{C}$ temperatures. The known weight of adsorbent material was added to $50 \mathrm{~mL}$ of the metal ion solutions with an initial concentration of $5 \mathrm{mg} / \mathrm{L}$ to $30 \mathrm{mg} / \mathrm{L}$. The contents were shaken thoroughly using a mechanical shaker rotating with a speed of $120 \mathrm{rpm}$. The solution was then filtered at preset time intervals and the residual metal ion concentration was measured.

\section{Effect of variable parameters}

\section{Dosage of adsorbents}

The various doses consisting of the adsorbents respectively mixed with the metal ions solutions and the mixture was agitated in a mechanical shaker. The adsorption capacities for different doses were determined at definite time intervals by keeping all other factors constant.

\section{Initial concentration of metal ion}

In order to determine the rate of adsorption, experiments were conducted with different initial concentrations of metal ions ranging from 5 to $30 \mathrm{mg} / \mathrm{L}$. All other factors have kept constant.

\section{Contact time}

The effect of period of contact on the removal of the metal ion on adsorbent in a single cycle was determined by keeping particle size, initial concentration, dosage, $\mathrm{pH}$ and concentration of other ions constant. 
$p H$

Adsorption experiments were carried out at $\mathrm{pH}$ 2,3,4,5,6,7,8,9 and 10. The acidic and alkaline $\mathrm{pH}$ of the media was maintained by adding the required amounts of dilute hydrochloric acid and sodium hydroxide solutions. The parameters like particle size of the adsorbents, metal ion concentration, dosage of the adsorbents and concentration of other ions have kept constant while carrying out the experiments. The $\mathrm{pH}$ of the samples was determined using a portable $\mathrm{pH}$ meter, Systronics make. The $\mathrm{pH}$ meter was calibrated with 4.0 and 9.2 buffers.

\section{Chloride}

The experiments were done in the presence of varying chloride environments using various chloride solutions. While doing the experiments, the absence of other anions has ensured.

\section{Temperature}

The adsorption experiments were performed at four different temperatures viz., 30, 40, 50 and $60^{\circ} \mathrm{C}$ in a thermostat attached with a shaker, Remi make. The constancy of the temperature was maintained with an accuracy of $\pm 0.5^{\circ} \mathrm{C}$.

\section{Zero point charge}

The $\mathrm{pH}$ at the potential of zero charge of the carbon was measured using the $\mathrm{pH}$ drift method. The $\mathrm{pH}$ of the solution was adjusted by using $0.01 \mathrm{M}$ sodium hydroxide or hydrochloric acid. Nitrogen was bubbled through the solution at $25^{\circ} \mathrm{C}$ to remove the dissolved carbon dioxide. Activated carbon $50 \mathrm{mg}$ was added to $50 \mathrm{~mL}$ of the solution. After stabilization, the final $\mathrm{pH}$ was recorded. The graphs of final $\mathrm{pH}$ versus initial $\mathrm{pH}$ used to determine the zero point charge of the activated carbon.

\section{Titration studies}

According to Boehm only strong acidic carboxylic acid groups are neutralized by sodium bicarbonate, where as those neutralized by sodium carbonate are thought to be lactones, lactol and carboxyl group. The weakly acidic phenolic groups only react with strong alkali, sodium hydroxide. Therefore, by selective neutralization using bases of different strength, the surface acidic functional group in carbon can be characterized both quantitatively and qualitatively. Neutralization with hydrochloric acid characterizes the amount of surface basic groups that are, for example, pyrones and chromenes. The basic properties have described to surface basic groups and the pi electron system of carbon basal planes. The results indicate that the activated carbons used may possesses acidic oxygen functional group on their surface and this is supported well by their respective zero point charge values. The results obtained from the above characterization studies are given in the Table 1.

Desorption studies

Desorption studies help to elucidate the nature of adsorption and recycling of the spent adsorbent and the metal ions. The effect of various reagents used for desorption are studied.

\section{Results and Discussion}

\section{Characterization of the adsorbent}

Activated carbons are a widely used adsorbent due to its high adsorption capacity, high surface area, micro porous structure and high degree of surface respectively. The wide usefulness of carbon is a result of their specific surface area, high chemical and mechanical stability. The chemical nature and pore structure usually determines the sorption activity. The physico chemical properties are listed in Table 1 
Table 1. Characteristics of the adsorbent

\begin{tabular}{lc}
\hline \multicolumn{1}{c}{ Properties } & PDC \\
\hline Particle size, mm & 0.06 \\
Density, g/cc & 0.3843 \\
Moisture content, \% & 0.85 \\
Loss on ignition, \% & 72 \\
Acid insoluble matter, \% & 1 \\
Water soluble matter, \% & 0.08 \\
pH of aqueous solution & 6.40 \\
$\mathrm{pH}_{\text {zpc }}$ & 6.10 \\
Surface groups, m equiv/g & \\
i) Carboxylic acid & 0.175 \\
ii) Lactone, lactol & 0.032 \\
iii) Phenolic & 0.042 \\
iv) Basic, pyrones and chromenes & 0.036 \\
\hline
\end{tabular}

\section{Effect of contact time and initial metal ion concentration}

The experimental results of adsorptions of at various concentrations $(5,10,15,20,25$ and $30 \mathrm{mg} / \mathrm{L})$ with contact time are shown in Figure 1. The equilibrium data were collected in Table 2, reveals that, percent adsorption decreased with increase in initial chromium ion concentration, but the actual amount of chromium ion adsorbed per unit mass of carbon increased with increase in chromium ion concentration. It means that the adsorption is highly dependent on initial concentration of chromium ion. It is because of that at lower concentration, the ratio of the initial number of chromium ion to the available surface area is low subsequently the fractional adsorption becomes independent of initial concentration. However, at high concentration the available sites of adsorption becomes fewer and hence the percentage removal of chromium ion is dependent upon initial concentration ${ }^{5,6}$. Equilibrium have established at 40 minutes for all concentrations. Figure 1 reveals that the curves are single, smooth, and continuous, leading to saturation, suggesting the possible monolayer coverage of the chromium ion on the carbon surface.

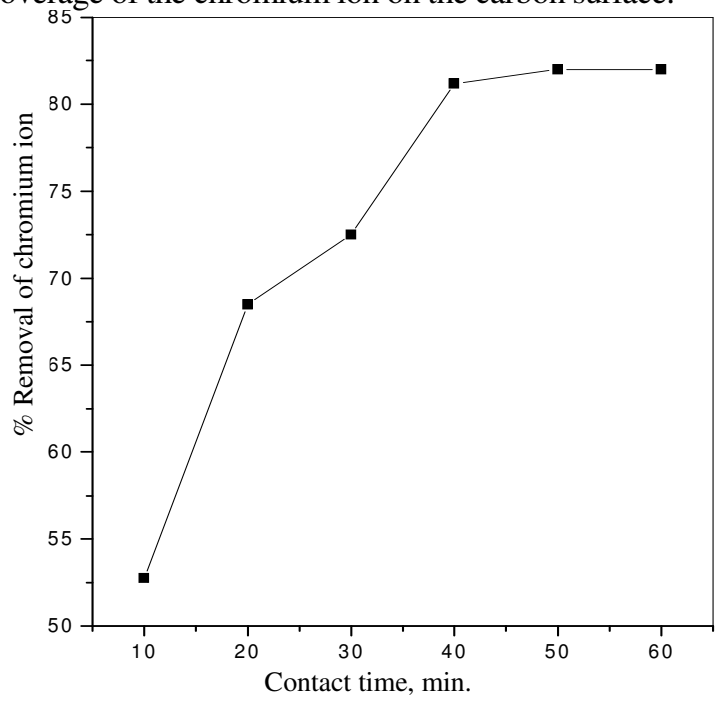

Figure 1. Effect of contact time on the removal of chromium ion by PDC $[\mathrm{Cr}]=20 \mathrm{mg} / \mathrm{L}$, $\mathrm{pH}=6.5$; Dose $=50 \mathrm{mg} / 50 \mathrm{~mL}$ 


\section{Effect of carbon concentration}

The adsorption of the chromium ion on carbon was studied by varying the carbon concentration $(25-250 \mathrm{mg} / 50 \mathrm{~mL})$ for $20 \mathrm{mg} / \mathrm{L}$ of chromium ion concentration. The percent adsorption increased with increase in the carbon concentration (Figure 2). This was attributed to increased carbon surface area and availability of more adsorption sites ${ }^{5,6}$. Hence remaining part of experiments is carried out with the adsorbent dose of $50 \mathrm{mg} / 50 \mathrm{~mL}$.

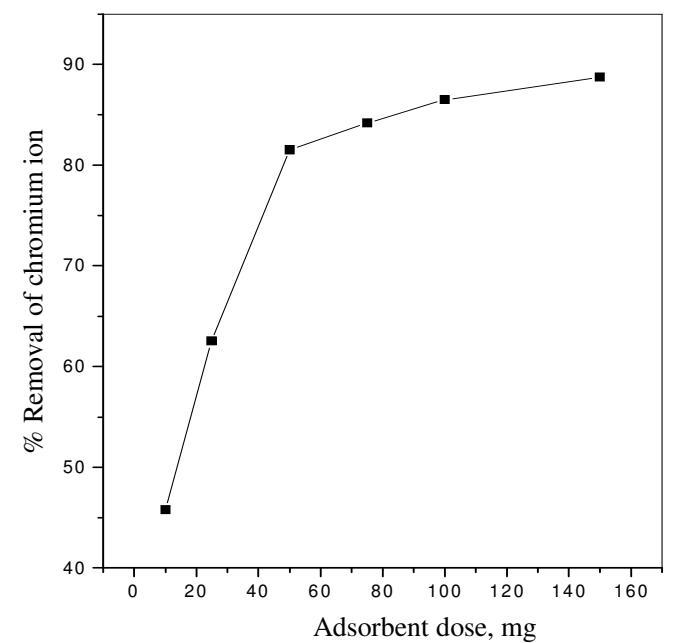

Figure 2. Effect of adsorbent dose on the removal of chromium ion by PDC $[\mathrm{Cr}]=20 \mathrm{mg} / \mathrm{L}$, $\mathrm{pH}=7$; Contact time $=60 \mathrm{~min}$

\section{Adsorption isotherm}

The experimental data analyzed according to the linear form of the Langmuir and Freundlich isotherms ${ }^{7,8}$.

The Langmuir isotherm represented by the following equation

$$
\mathrm{C}_{\mathrm{e}} / \mathrm{Q}_{\mathrm{e}}=1 / \mathrm{Q}_{\mathrm{m}} \mathrm{b}+\mathrm{C}_{\mathrm{e}} / \mathrm{Q}_{\mathrm{m}}
$$

Where $C_{e}$ is the equilibrium concentration $(\mathrm{mg} / \mathrm{L}), \mathrm{Q}_{\mathrm{e}}$ is the amount adsorbed at equilibrium ( $\mathrm{mg} / \mathrm{g}$ ) and $\mathrm{Q}_{\mathrm{m}}$ and $\mathrm{b}$ is Langmuir constants related to adsorption efficiency and energy of adsorption, respectively. The linear plots of $\mathrm{C}_{\mathrm{e}} / \mathrm{Q}_{\mathrm{e}}$ versus $\mathrm{C}_{\mathrm{e}}$ suggest the applicability of the Langmuir isotherms (Figure 3). Values of $\mathrm{Q}_{\mathrm{m}}$ and $\mathrm{b}$ were determined from slope and intercepts of the plots and are presented in Table 2. From the results, it is clear that the value of adsorption efficiency $\mathrm{Q}_{\mathrm{m}}$ and adsorption energy $\mathrm{b}$ of the carbon increases on increasing the temperature. The observed $\mathrm{Q}_{\mathrm{m}}$ values conclude that the maximum adsorption corresponds to a saturated monolayer of adsorbate molecules on adsorbent surface with constant energy and no transmission of adsorbate in the plane of the adsorbent surface. The observed $b$ values shows that the adsorbent prefers to bind acidic ions and that speciation predominates on sorbent characteristics, when ion exchange is the predominant mechanism takes place in the adsorption of chromium ion. Further, it confirms the endothermic nature of the process involved in the system ${ }^{9,10,11}$. To confirm the favourability of the adsorption process, the separation factor $\left(\mathrm{R}_{\mathrm{L}}\right)$ has calculated and presented in Table 4 . The values were found to be between 0 and 1 and confirm that the ongoing adsorption process is favorable ${ }^{12}$.

The Freundlich equation was also employed for the adsorption of chromium ion on the adsorbent. The Freundlich isotherm have represented as

$$
\log \mathrm{Q}_{\mathrm{e}}=\log \mathrm{K}_{\mathrm{f}}+1 / \mathrm{n} \log \mathrm{C}_{\mathrm{e}}
$$




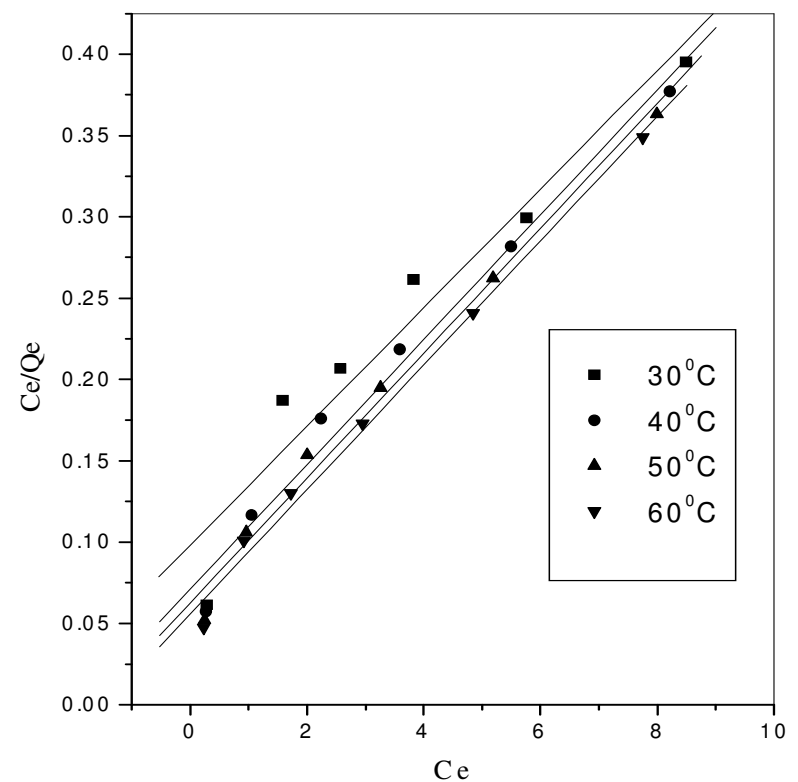

Figure 3. Langmuir adsorption isotherm for the adsorption of chromium ion onto PDC

Table 2. Equilibrium Parameters for the adsorption of chromium ion on to acid activated Carbon

\begin{tabular}{ccccccccccccc}
\hline \multirow{2}{*}{$\begin{array}{c}\text { Cr ion } \\
\mathrm{mg} / \mathrm{L}\end{array}$} & \multicolumn{4}{c}{$\mathrm{Ce}, \mathrm{mg} / \mathrm{L}$} & \multicolumn{4}{c}{$\mathrm{Qe}, \mathrm{mg} / \mathrm{g}$} & \multicolumn{3}{c}{ Metal ion Removed, \% } \\
\hline 5 & $30^{\circ}$ & $40^{\circ}$ & $50^{\circ}$ & $60^{\circ}$ & $30^{\circ}$ & $40^{\circ}$ & $50^{\circ}$ & $60^{\circ}$ & $30^{\circ}$ & $40^{\circ}$ & $50^{\circ}$ & $60^{\circ}$ \\
\hline 10 & 0.2884 & 0.2676 & 0.2458 & 0.2245 & 4.7116 & 4.7324 & 4.7542 & 4.7755 & 94.2 & 94.6 & 95.1 & 95.3 \\
15 & 1.5758 & 1.0454 & 0.9558 & 0.9146 & 8.4242 & 8.9546 & 9.0442 & 9.0854 & 84.2 & 89.5 & 90.4 & 90.8 \\
20 & 3.8245 & 2.2456 & 1.9948 & 1.5446 & 12.4321 & 12.7544 & 13.0052 & 13.2746 & 82.8 & 85.0 & 86.7 & 88.4 \\
25 & 5.7587 & 5.4934 & 3.2574 & 2.9472 & 16.1755 & 16.4124 & 16.7426 & 17.0528 & 80.8 & 82.1 & 83.7 & 85.2 \\
30 & 8.4949 & 8.2159 & 7.9882 & 7.7572 & 21.5051 & 21.7851 & 22.0118 & 22.2428 & 71.6 & 72.6 & 73.3 & 74.1 \\
\hline
\end{tabular}


Where $Q_{e}$ is the amount of chromium ion adsorbed (mg/g), $C_{e}$ is the equilibrium concentration of chromium ion in solution $(\mathrm{mg} / \mathrm{L})$ and $\mathrm{K}_{\mathrm{f}}$ and $\mathrm{n}$ are constants incorporating all factors affecting the adsorption capacity and intensity of adsorption, respectively. Linear plots of $\log \mathrm{Q}_{\mathrm{e}}$ versus $\log \mathrm{C}_{\mathrm{e}}$ shows that the adsorption of chromium ion follows the Freundlich isotherm (Figure 4). The found values of $K_{f}$ and $n$ have given in the Table 5 shows that the increase in negative charges on the adsorbent surface, that makes electrostatic force like Vanderwaal's between the carbon surface and chromium ion. This increases the adsorption of chromium ion. The higher atomic weight, large size and radii of the chromium ion have limits the possibility of the adsorption of chromium ion onto adsorbent in higher concentration. However, the values clearly show the dominance in adsorption capacity. The intensity of adsorption is an indicative of the bond energies between chromium ion and adsorbent and the possibility of slight chemisorptions rather than physisorption of chromium ion. However, the multilayer adsorption of chromium ion through the percolation process may be possible. The values of $n$ is greater than one indicating the adsorption is much more favorable ${ }^{11,12}$.

Table 3. Langmuir isotherm Results

\begin{tabular}{ccccc}
\hline & $\begin{array}{c}\text { Temp } \\
{ }^{\circ} \mathrm{C}\end{array}$ & $\begin{array}{c}\text { Statistical para meters } \\
\mathrm{r}^{2}\end{array}$ & $\mathrm{Q}_{\mathrm{m}}$ & $\begin{array}{c}\text { Constants } \\
\mathrm{b}\end{array}$ \\
\hline \multirow{4}{*}{ Cr ion } & 30 & 0.9651 & 27.403 & 0.3715 \\
& 40 & 0.9913 & 26.061 & 0.5401 \\
& 50 & 0.9940 & 26.063 & 1.6366 \\
& 60 & 0.9954 & 26.171 & 1.4667 \\
\hline
\end{tabular}

Table 4. Dimensionless separation factor $\left(\mathrm{R}_{\mathrm{L}}\right)$

\begin{tabular}{ccccc}
\hline Cr ion,mg/L & \multicolumn{4}{c}{ Temperature, ${ }^{\circ} \mathrm{C}$} \\
\cline { 2 - 5 } & 30 & 40 & 50 & 60 \\
\hline 5 & 0.34 & 0.27 & 0.11 & 0.12 \\
10 & 0.21 & 0.15 & 0.05 & 0.06 \\
15 & 0.15 & 0.10 & 0.03 & 0.04 \\
20 & 0.12 & 0.08 & 0.03 & 0.03 \\
25 & 0.09 & 0.07 & 0.02 & 0.03 \\
30 & 0.08 & 0.06 & 0.02 & 0.02 \\
\hline
\end{tabular}

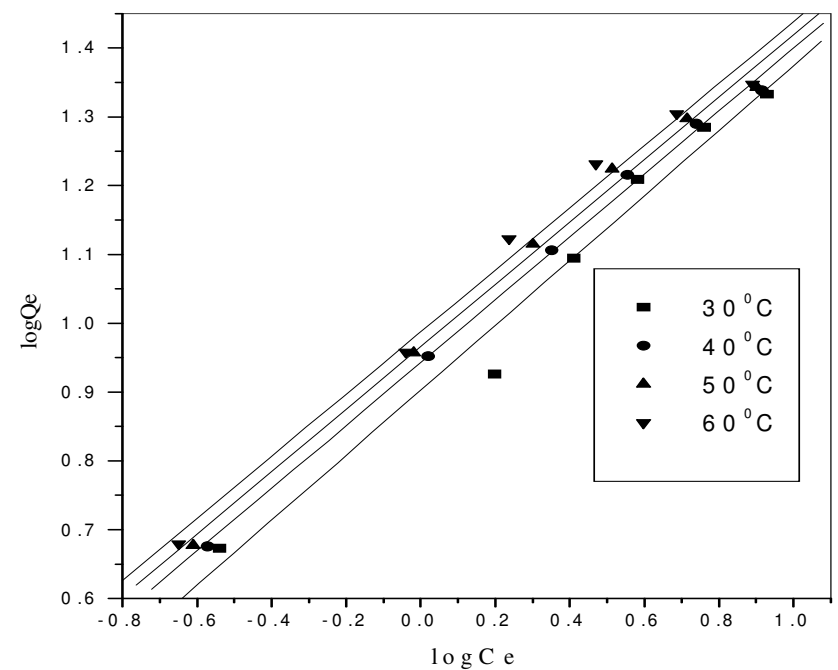

Figure 4. Freundlich adsorption isotherm for the removal of chromiumion onto PDC 
Table 5. Freundlich isotherm Results

\begin{tabular}{ccccc}
\hline & $\begin{array}{c}\text { Temp } \\
{ }^{\circ} \mathrm{C}\end{array}$ & $\begin{array}{c}\text { Statistical para meters } \\
\mathrm{r}^{2}\end{array}$ & $\mathrm{~K}_{\mathrm{f}}$ & $\begin{array}{c}\text { Constants } \\
\mathrm{n}\end{array}$ \\
\hline \multirow{4}{*}{ Cr ion } & $30^{\circ}$ & 0.9884 & 1.6027 & 2.1196 \\
& $40^{\circ}$ & 0.9983 & 1.5794 & 2.1874 \\
& $50^{\circ}$ & 0.9967 & 1.5738 & 2.2046 \\
& $60^{\circ}$ & 0.9946 & 1.5719 & 2.2108 \\
\hline
\end{tabular}

\section{Effect of temperature}

The adsorption capacity of the carbon increased with increase in the temperature of the system from $30^{\circ}-60^{\circ} \mathrm{C}$. Thermodynamic parameters such as change in free energy $\left(\Delta \mathrm{G}^{\circ}\right)(\mathrm{kJ} / \mathrm{mol})$, enthalpy $\left(\Delta \mathrm{H}^{\circ}\right)(\mathrm{kJ} / \mathrm{mol})$ and entropy $\left(\Delta \mathrm{S}^{\circ}\right)(\mathrm{J} / \mathrm{K} / \mathrm{mol})$ were determined using the following equations

$$
\begin{aligned}
\mathrm{K}_{0} & =\mathrm{C}_{\text {solid }} / \mathrm{C}_{\text {liquid }} \\
\Delta \mathrm{G}^{\circ} & =-\mathrm{RT} \ln \mathrm{K}_{\mathrm{O}} \\
\operatorname{Iog} \mathrm{K}_{0} & =\Delta \mathrm{S}^{\circ} /(2.303 \mathrm{RT})-\Delta \mathrm{H}^{\circ} /(2.303 \mathrm{RT})
\end{aligned}
$$

Where $\mathrm{K}_{\mathrm{o}}$ is the equilibrium constant, $\mathrm{C}_{\text {solid }}$ is the solid phase concentration at equilibrium $(\mathrm{mg} / \mathrm{L}), \mathrm{C}_{\text {liquid }}$ is the liquid phase concentration at equilibrium $(\mathrm{mg} / \mathrm{L}), \mathrm{T}$ is the temperature in Kelvin and $\mathrm{R}$ is the gas constant. The $\Delta \mathrm{H}^{\circ}$ and $\Delta \mathrm{S}^{\circ}$ values obtained from the slope and intercept of Van't Hoff plots have presented in Table 6. The values $\Delta \mathrm{H}^{\circ}$ are with in the range of 1 to 93 $\mathrm{KJ} / \mathrm{mol}$ indicates the physisorption. From the results we could make out that physisorption is much more favorable for the adsorption of chromium ion. The positive values of $\Delta \mathrm{H}^{\circ}$ show the endothermic nature of adsorption and it governs the possibility of physical adsorption. Because in the case of physical adsorption, while increasing the temperature of the system, the extent of chromium ion adsorption increases, this rules out the possibility of chemisorption ${ }^{12-14}$. The low $\Delta \mathrm{H}^{\circ}$ value depicts chromium ion are physisorbed onto adsorbent PDC.

The negative values of $\Delta \mathrm{G}^{\circ}$ (Table 6) shows the adsorption is highly favorable and spontaneous. The positive values of $\Delta \mathrm{S}^{\circ}$ (Table 6) shows the increased disorder and randomness at the solid solution interface of chromium ion with PDC, while the adsorption there are some structural changes in the chromium ion and the adsorbent occur. The adsorbed water molecules, which have displaced by the adsorbate species, gain more translational entropy than is lost by the adsorbate molecules, thus allowing the prevalence of randomness in the system. The enhancement of adsorption capacity of the activated carbon at higher temperatures was attributed to the enlargement of pore size and activation of the adsorbent surface ${ }^{12,13}$.

\section{Kinetics of adsorption}

The kinetics of sorption describes the solute uptake rate, which in turn governs residence time or sorption reaction. It is one of the important characteristics in defining the efficiency or sorption. In the present study, the kinetics of the chromium ion removal was carried out to understand the behaviour of these low cost carbon adsorbents. The adsorption of chromium ion from an aqueous follows reversible first order kinetics, when a single species are considered on a heterogeneous surface. The heterogeneous equilibrium between the chromium ion solutions and the activated carbon are expressed as



Where $\mathrm{k}_{1}$ is the forward rate constant and $\mathrm{k}_{2}$ is the backward rate constant. A represents chromium ion remaining in the aqueous solution and $\mathrm{B}$ represent chromium ion adsorbed on the surface of activated carbon. The equilibrium constant $\left(\mathrm{K}_{0}\right)$ is the ration of the concentration adsorbate in adsorbent and in aqueous solution $\left(\mathrm{K}_{0}=\mathrm{k}_{1} / \mathrm{k}_{2}\right)$. 
In order to study the kinetics of the adsorption process under consideration the following kinetic equation proposed by Natarajan and Khalaf as cited in literature has been employed ${ }^{1}$.

$$
\log \mathrm{C}_{0} / \mathrm{C}_{\mathrm{t}}=\left(\mathrm{K}_{\mathrm{ad}} / 2.303\right) \mathrm{t}
$$

Where $\mathrm{C}_{0}$ and $\mathrm{C}_{\mathrm{t}}$ are the concentration of the chromium ion in (in $\mathrm{mg} / \mathrm{L}$ ) at time zero and at time $\mathrm{t}$, respectively. The rate constants $\left(\mathrm{K}_{\mathrm{ad}}\right)$ for the adsorption processes have been calculated from the slope of the linear plots of $\log \mathrm{C}_{0} / \mathrm{C}_{\mathrm{t}}$ versus $\mathrm{t}$ for different concentrations and temperatures. The determination of rate constants as described in literature given by

$$
\mathrm{K}_{\mathrm{ad}}=\mathrm{k}_{1}+\mathrm{k}_{2}=\mathrm{k} 1+\left(\mathrm{k}_{1} / \mathrm{K}_{0}\right)=\mathrm{k}_{1}\left[1+1 / \mathrm{K}_{0}\right]
$$

Table 6. Equilibrium constant and thermodynamic parameters for the adsorption of chromium ion onto acid activated carbon

\begin{tabular}{ccccccccccc}
\hline $\begin{array}{c}\text { Cr ion, } \\
\mathrm{mg} / \mathrm{L}\end{array}$ & $30^{\circ} \mathrm{C}$ & $40^{\circ} \mathrm{C}$ & $50^{\circ} \mathrm{C}$ & $60^{\circ} \mathrm{C}$ & $30^{\circ} \mathrm{C}$ & $40^{\circ} \mathrm{C}$ & $50^{\circ} \mathrm{C}$ & $60^{\circ} \mathrm{C}$ & $\Delta \mathrm{H}^{\circ}$ & $\Delta \mathrm{S}^{\circ}$ \\
\hline 5 & 16.33 & 17.63 & 19.34 & 21.27 & -7.04 & -7.46 & -7.95 & -8.46 & 7.33 & 47.33 \\
10 & 5.34 & 8.56 & 9.46 & 9.93 & -4.22 & -5.58 & -6.03 & -6.35 & 16.61 & 69.63 \\
15 & 4.84 & 5.67 & 6.51 & 7.69 & -3.97 & -4.65 & -5.03 & -5.64 & 12.68 & 54.92 \\
20 & 4.22 & 4.57 & 5.13 & 5.78 & -3.62 & -3.95 & -4.39 & -4.85 & 8.75 & 40.70 \\
25 & 3.34 & 3.55 & 3.81 & 4.15 & -3.04 & -3.29 & -3.59 & -3.93 & 5.97 & 29.66 \\
30 & 2.53 & 2.65 & 2.75 & 2.86 & -2.33 & -2.61 & -2.71 & -2.90 & 3.36 & 18.82 \\
\hline
\end{tabular}

The overall rate constant $\mathrm{k}_{\mathrm{ad}}$ for the adsorption of chromium ion at different temperatures are calculated from the slopes of the linear Natarajan-Khalaf plots. The rate constant values are collected in Table 7 shows that the rate constant $\left(\mathrm{k}_{\mathrm{ad}}\right)$ increases with increase in temperature suggesting that the adsorption process in endothermic in nature. Further, $\mathrm{k}_{\mathrm{ad}}$ values decrease with increase in initial concentration of the chromium ion. In cases of strict surface adsorption a variation of rate should be proportional to the first power of concentration. However, when pore diffusion limits the adsorption process, the relationship between initial chromium ion concentration and rate of reaction will not be linear. Thus, in the present study pore diffusion limits the overall rate of chromium ion adsorption. The over all rate of adsorption is separated into the rate of forward and reverse reactions using the above equation. The rate constants for the forward and reverse processes are also collected in Table 7 indicate that, at all initial concentrations and temperatures, the forward rate constant is much higher than the reverse rate constant suggesting that the rate of adsorption is clearly dominant ${ }^{1,11,13}$.

\section{Intraparticle diffusion}

The most commonly used technique for identifying the mechanism involved in the sorption process is by fitting the experimental data in an intraparticle diffusion plot. Previous studies by various researchers showed that the plot of Qt versus $t^{0.5}$ represents multi linearity, which characterizes the two or more steps involved in the sorption process. According to Weber and Morris, an intraparticle diffusion coefficient $\mathrm{K}_{\mathrm{p}}$ is defined by the equation:

$$
\mathrm{K}_{\mathrm{p}}=\mathrm{Q} / \mathrm{t}^{0.5}
$$

Thus the $\mathrm{K}_{\mathrm{p}}\left(\mathrm{mg} / \mathrm{g} \min ^{0.5}\right)$ value can be obtained from the slope of the plot of Qt $(\mathrm{mg} / \mathrm{g})$ versus $\mathrm{t}^{0.5}$ for chromium ion. From figure 5 , it was noted that the sorption process tends to be followed by two phases. The two phases in the intraparticle diffusion plot suggest that the sorption process proceeds by surface sorption and intraparticle diffusion ${ }^{15,16}$. The initial curved portion of the plot indicates a boundary layer effect while the second linear portion is due to intraparticle or pore diffusion. The slope of the second linear portion of the plot has been defined as the intraparticle diffusion parameter $\mathrm{K}_{\mathrm{p}}\left(\mathrm{mg} / \mathrm{g} \mathrm{min}^{0.5}\right)$. On the other hand, the intercept of the plot reflects the boundary layer effect. The larger the intercept, the greater is the contribution of the surface sorption in the rate limiting step. The calculated intraparticle diffusion coefficient $K_{\mathrm{p}}$ value was given by $0.036,0.258,0.249,0.226$ and $0.248 \mathrm{mg} / \mathrm{g} \mathrm{min}{ }^{0.5}$ for initial chromium ion concentration of $5,10,15,20,25$ and $30 \mathrm{mg} / \mathrm{L}$ at $30^{\circ} \mathrm{C}$. 
Table 7. Rate constants for the adsorption of chromium ion $\left(10^{3} \mathrm{k}_{\mathrm{ad}}, \mathrm{min}^{-1}\right)$ and the constants for forward $\left(10^{3} \mathrm{k}_{1}, \mathrm{~min}^{-1}\right)$ and reverse $\left(10^{3} \mathrm{k}_{2}, \mathrm{~min}^{-1}\right)$ process

\begin{tabular}{|c|c|c|c|c|c|c|c|c|c|c|c|c|}
\hline \multirow{3}{*}{$\begin{array}{c}\mathrm{Cr} \text { ion, } \\
\mathrm{mg} / \mathrm{L}\end{array}$} & \multicolumn{12}{|c|}{ Temperature, ${ }^{\circ} \mathrm{C}$} \\
\hline & \multicolumn{4}{|c|}{$\mathrm{k}_{\mathrm{ad}}$} & \multirow{2}{*}{\multicolumn{2}{|c|}{$\frac{\mathrm{k}_{1} \quad \mathrm{k}_{2}}{30}$}} & $\mathrm{k}_{1}$ & $\mathrm{k}_{2}$ & $\mathrm{k}_{1}$ & $\mathrm{k}_{2}$ & $\mathrm{k}_{1}$ & $\mathrm{k}_{2}$ \\
\hline & 30 & 40 & 50 & 60 & & & \multicolumn{2}{|c|}{40} & \multicolumn{2}{|c|}{50} & \multicolumn{2}{|c|}{60} \\
\hline 5 & 6.21 & 7.84 & 46.68 & 48.46 & 5.86 & 0.35 & 7.42 & 0.42 & 44.5 & 2.30 & 46.67 & 2.19 \\
\hline 10 & 11.91 & 17.38 & 19.22 & 18.84 & 10.04 & 1.88 & 15.58 & 1.81 & 17.39 & 1.83 & 17.12 & 1.72 \\
\hline 15 & 10.49 & 27.66 & 10.18 & 10.82 & 8.70 & 1.79 & 23.52 & 4.14 & 8.83 & 1.35 & 9.57 & 1.24 \\
\hline 20 & 6.24 & 8.75 & 7.08 & 6.19 & 5.05 & 1.19 & 7.18 & 1.57 & 5.92 & 1.15 & 5.28 & 0.91 \\
\hline 25 & 4.06 & 4.46 & 4.67 & 3.88 & 3.13 & 0.93 & 3.48 & 0.98 & 3.70 & 0.97 & 3.13 & 0.75 \\
\hline 30 & 2.47 & 2.86 & 3.03 & 2.48 & 1.78 & 0.69 & 2.08 & 0.78 & 2.23 & 0.80 & 1.84 & 0.64 \\
\hline & & & 4.30 & & & & & & & & & \\
\hline & & & & & & & & & & & & \\
\hline & & & & 3 & $\frac{1}{4}$ & $\begin{array}{l}1 \\
5\end{array}$ & 6 & 7 & 8 & & & \\
\hline
\end{tabular}

Figure 5. Inteaparticle diffusion effect on the adsorption of chromiumion onto $\mathrm{PDC}[\mathrm{Cr}]=20$ $\mathrm{mg} / \mathrm{L}, \mathrm{pH}=7$; Dose $=50 \mathrm{mg} / 50 \mathrm{~mL}$.

Effect of $p H$

The experiments carried out at different initial $\mathrm{pH}$ show that the adsorption percentage increases with increase in initial $\mathrm{pH}$ of the medium in the range studied i.e. 3 to 10 as depicted in the Figure 6. This behaviour can be explained using $\mathrm{pH}_{\mathrm{ZPC}}$ of the adsorbent. In the present study the $\mathrm{pH}_{\mathrm{ZPC}}$ of Pandanus carbon is 6.1. At any $\mathrm{pH}$ below $\mathrm{pH}_{\mathrm{ZPC}}$, the surface of adsorbent is positively charged and at $\mathrm{pH}$ above $\mathrm{pH}_{\mathrm{ZPC}}$, the surface is negative. When the solution $\mathrm{pH}$ exceeded $\mathrm{pH}_{\mathrm{ZPC}}$, the chromium ions are more easily attracted by the negatively charged surface of adsorbent, favoring accumulation of chromium ion on the surface and thus promoting adsorption. In addition the increase is partially attributed to the formation of different hydroxo species with rise in solution ${ }^{1,12}$. The decrease in adsorption of metal ions at low $\mathrm{pH}$ can be attributed to the competition between $\mathrm{H}^{+}$and metal ions. It is thus clear from Figure 6 that at lower $\mathrm{pH}$, the adsorption of chromium ion studied is drastically reduced. This observation was made use of to desorb the chromium ion from the adsorbed material.

\section{Effect of the ionic strength on the adsorption of chromium ion on PDC}

The effect of sodium chloride on the adsorption of chromium ion on PDC is shown in Figure 7. In a low solution concentration $\mathrm{NaCl}$ had little influence on the adsorption capacity. At higher ionic strength the adsorption chromium of ion on PDC will be increased due to the partial neutralization of the positive charge on the carbon surface and a consequent compression of the electrical double layer by the $\mathrm{Cl}^{-}$anion. The chloride ion can also enhance adsorption of chromium ion on PDC by pairing of their charges and hence reducing the repulsion between the chromium ions adsorbed on the surface ${ }^{1,17}$. This initiates carbon to adsorb more of positive chromium ions. 




Figure 6. Effect of initial $\mathrm{pH}$ on the removal of chromium ion by $\mathrm{PDC}[\mathrm{Cr}]=20 \mathrm{mg} / \mathrm{L}$, Dose $=50 \mathrm{mg} / 50 \mathrm{~mL}$; Contact time $=60 \mathrm{~min}$

\section{Desorption studies}

Desorption studies help to elucidate the nature of adsorption and recycling of the spent adsorbent and the chromium ions. If the adsorbed chromium ions can be desorbed using neutral $\mathrm{pH}$ water, then the attachment of the chromium ions of the adsorbent is by weak bonds. If sulphuric acid or alkaline water desorp the chromium ion then the adsorption is by ion exchange. If organic acids, like acetic acid can desorp the chromium ions, then the chromium ions has held by the adsorbent through chemisorption ${ }^{12,18}$. The effect of various reagents used for desorption studies indicate that hydrochloric acid is a better reagent for desorption, because we could get more than $75 \%$ removal of adsorbed chromium ions. The reversibility of adsorbed chromium ions in mineral acid or base is in agreement with the $\mathrm{pH}$ dependent results obtained. The desorption of chromium ions by mineral acids and alkaline medium indicates that the chromium ions were adsorbed onto the activated carbon through by physisorption mechanisms.

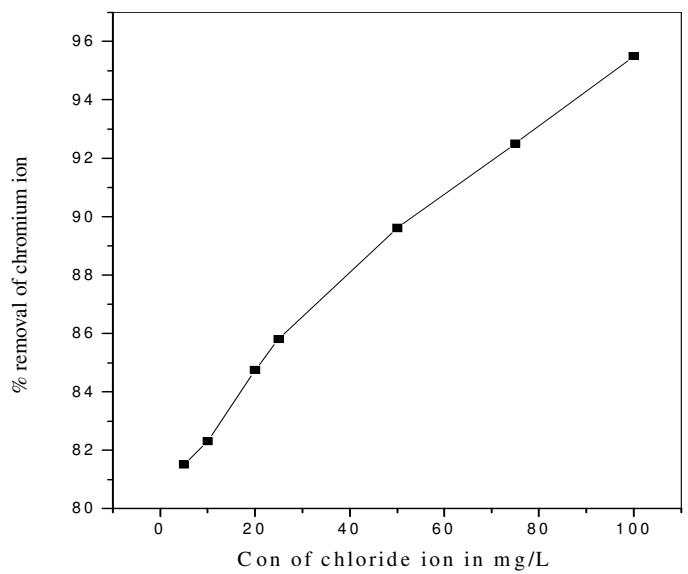

Figure 7. Effect of ionic strength on the adsorption of chromium ion onto $\mathrm{PDC}[\mathrm{Cr}]=20 \mathrm{mg} / \mathrm{L}$, $\mathrm{pH}=7$; Dose $=50 \mathrm{mg} / 50 \mathrm{~mL}$ 


\section{Conclusions}

The experimental data correlated reasonably well by the Langmuir and Freundlich adsorption isotherms and the isotherm parameters were calculated. The low as well high $\mathrm{pH}$ value pay the way to the optimum amount of adsorption of chromium ion. The amount of chromium ion adsorbed increased with increasing ionic strength and increased with increase in temperature. The dimensionless separation factor $\left(\mathrm{R}_{\mathrm{L}}\right)$ showed that the activated carbon could be used for the removal of chromium ion from aqueous solution. The values of $\Delta \mathrm{H}^{\circ}$, $\Delta \mathrm{S}^{\circ}$ and $\Delta \mathrm{G}^{\circ}$ results shows that the carbon employed has a considerable potential as an adsorbent for the removal of chromium ion

\section{Acknowledgement}

The authors acknowledge sincere thanks to Mrs. Mala Arivoli, The Principal, M. R. Government Arts College, Mannargudi and The Director of Collegiate Education, Chennai for carrying out this research work successfully.

\section{References}

1. Arivoli S, Kinetic and thermodynamic studies on the adsorption of some metal ions and dyes onto low cost activated carbons, Ph D., Thesis, Gandhigram Rural University, Gandhigram, 2007.

2. Sekaran G, Shanmugasundaram K A, Mariappan M and Raghavan K V, Indian J Chem Technol., 1995, 2, 311.

3. Selvarani K, Studies on Low cost Adsorbents for the removal of organic and Inorganics from Water, Ph D., Thesis, Regional Engineering College, Thiruchirapalli, 2000.

4. Jia Y F and Thomas K K, Langmuir, 2002, 18, 470-478.

5. Namasivayam C, Muniasamy N, Gayathri K, Rani M and Renganathan K, Biores Technol, 1996, 57, 37.

6. Namasivayam C and Yamuna R T, Environ Pollut., 1995, 89, 1.

7. Langmuir I, J Am Chem Soc., 1918, 40, 1361.

8. Freundlich H, Phys Chemie., 1906, 57, 384.

9. Krishna D G and Bhattacharyya G, Appl Clay Sci., 2002, 20, 295.

10. Arivoli S, Viji Jain M and Rajachandrasekar T, Mat Sci Res India, 2006, 3, 241-250.

11. Arivoli S and Hema M, Int J Phys Sci., 2007, 2, 10-17.

12. Arivoli S, Venkatraman B R, Rajachandrasekar T and Hema M, Res J Chem Environ. 2007, 17, 70-78.

13. Arivoli S, Kalpana K, Sudha R and Rajachandrasekar T, E J Chem, 2007, 4, 238-254.

14. Renmin Gong, Yingzhi Sun, Jian Chen, Huijun Liu, Chao yang, Dyes and Pigments, 2005, 67, 179.

15. Vadivelan V and Vasanthkumar K, J Colloid Interf Sci, 2005, 286, 91.

16. Weber W J, Principle and Application of Water Chemistry, Edited by Faust S D and Hunter J V Wiley, New York, 1967.

17. Yupeng Guo, Jingzhu Zhao, Hui Zhang, Shaofeng Yang, Zichen Wang and Hongding $\mathrm{Xu}$, Dyes and Pigments, 2005, 66, 123-128.

18. Sreedhar M K and Anirudhan T S, Indian J Environ Protect, 1999, 19, 8. 


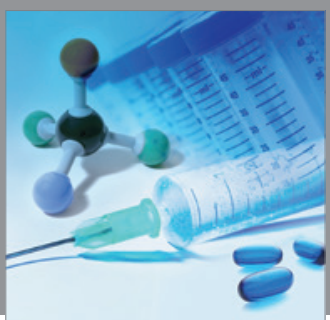

International Journal of

Medicinal Chemistry

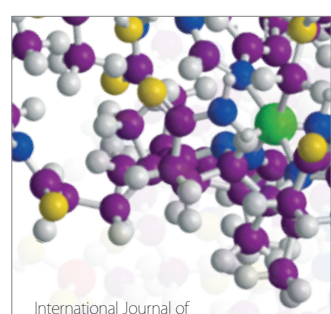

Carbohydrate Chemistry

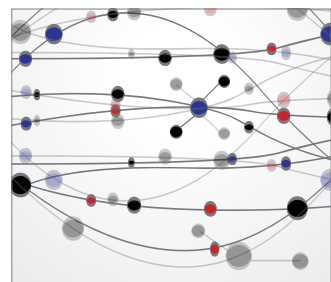

The Scientific World Journal
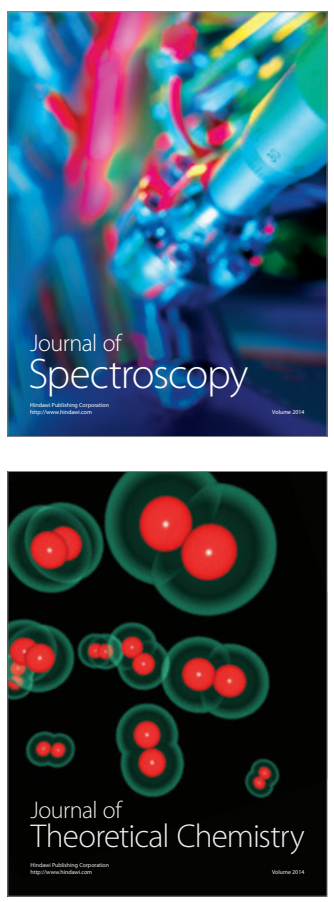


Submit your manuscripts at

http://www.hindawi.com
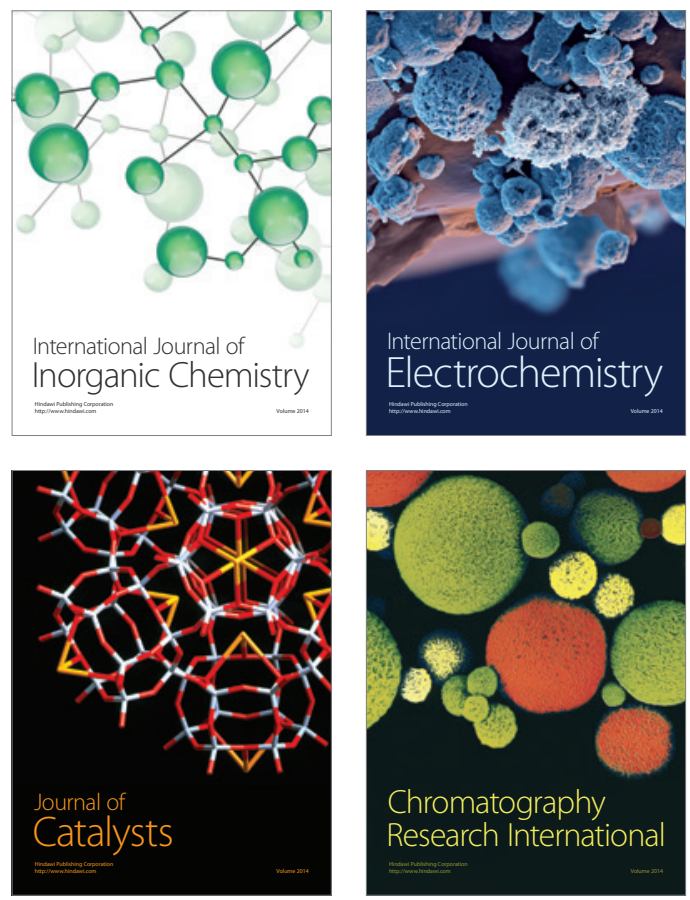
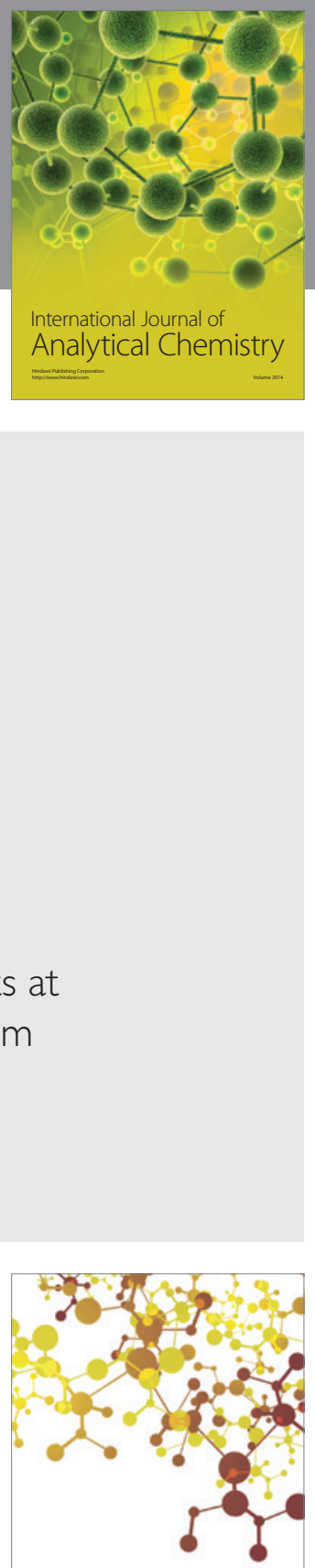

Journal of

Applied Chemistry
